Canadian Studies in Population, Vol. 31(1), 2004, pp. 1-14

\title{
The Canadian Population Society at Age Thirty: A Retrospective and Prospective
}

\author{
Frank Trovato \\ Department of Sociology \\ University of Alberta \\ Edmonton, Alberta \\ Presidential Address, Canadian Population Society \\ University of Manitoba, Winnibeg, Manitoba \\ June 4, 2004
}

\section{Introduction}

As I read through a recent issue of Scientific American, an interesting article by Gabriele Veneziano caught my attention. He is a leading authority on string theory---a theory in physics that tries to explain the elemental basis of matter in the universe. Although I can not claim expert knowledge of the subject matter of Veneziano's article, I found it of great interest for its illumination on a most fascinating question: "Did time exist before the so-called 'big bang' at the beginning of the universe?" Also intriguing in Veneziano's paper are the opening sentences, which as we shall see later, touch on the topic of my address. In 1897, Veneziano wrote, the French post-impressionist painter, Paul Gauguin, painted one of the most famous works in modern art, titled: D'ou Venomnsnous? Que Sommes-nous? Ou allons nous?" Where do we come from? What are we? Where are we going? As suggested by this evocative title, the painting depicts the cycle of origin, identity, and destiny. ${ }^{1}$ I ask these same questions of the CPS as a professional association at the threshold of its third decade of existence. 
Frank Trovato

My involvement in the CPS spans a quarter century. In 1979, as a graduate student, I presented my first paper at a professional conference; it was the CPS meetings in Saskatoon, which were held as part of the Learned Societies Conference at the University of Saskatchewan. As the $15^{\text {th }}$ outgoing President of the CPS, I felt compelled to give a retrospective and prospective look at our association as it turns 30 , or as we say in common parlance, early adulthood. Age 30 is an important signifier in demography, as it represents, roughly, the average length of a generation---the average age at which the parental generation gives birth to its progeny. I suppose I could have chosen as the topic of my address something from my own research; or perhaps I could have given a review of the state of the literature in some area of our field. But I felt that a retrospective overview, followed by a prospective assessment of our fortunes would be a refreshing change from one and-a-half days of research presentations, though excellent, while at the same time help to instill a collective sense of where we are and where we are going as a community of experts.

\section{Origins}

Thirty years have passed since the beginning of the CPS in 1974. Much has changed since that time: the discipline of demography has undergone major shifts in orientation and approaches to research, as have the social sciences in general. Demography has been moving away from its predominant traditional macro level approach to research, and is shifting increasingly in favor of micro data analysis on a wide variety of topics that far expand the traditional boundaries of the discipline: overpopulation and development; demography transition; fertility, mortality and migration analysis; population estimates and projections. Judging from the contents of the mainstream journals in our discipline (i.e., Demography, Population Studies, Population and Development Review), one now finds a host of additional concerns spanning diverse topics. For instance, there is growing interest in the bio-demographic foundations of demographic action; and in the area of fertility and family planning, researchers are increasingly relying on anthropological approaches to better understand the micro level foundations of fertility decision making. Also important is an emphasis on the analysis of micro longitudinal data sets, which by their very nature, cover much more ground than could be imagined with the use of more traditional sources of data, namely census and vital statistics.

Since demography in Canada (and in the United States) is mainly taught within sociology departments, it is important to look at the broader social science scene in order to gain some appreciation of demography's current academic status. ${ }^{2}$ My understanding of the situation suggests that over recent years the quantitative side of sociology as a discipline has been diminished considerably. ${ }^{3}$ 
The Canadian Population Society at Age Thirty: A Retrospective and Prospective

(The situation in Europe and in the United States may be quite different.) ${ }^{4}$ The current emphasis across many sociology departments in Canada seems to be on the postmodernist perspective as a dominant paradigm to sociological analysis, and quantitative approaches, including demography, are being increasingly marginalized. ${ }^{5}$ As a perspective among other conceptual frameworks, postmodernism does have a certain value, as it represents another way of looking at the social world. The main problem, as I understand it, is that postmodernism is receiving overwhelming attention to the almost total exclusion of more traditional areas of sociology, demography included. ${ }^{6}$ The marginalization of demography within sociology would have indirect implications for the future of the CPS. I will return to this point later. I now turn to the question of the origins of the CPS and how it has changed over the first three decades of its existence.

\section{The Early Years}

In the introductory issue of Canadian Studies in Population, Betty MacLeod (1974:147), who served as president of the CPS between 1976 and 1978, announced that:

Recently, a new organization of professional demographers came into existence in Canada. Its name is the Canadian Population Society, and its charter membership consists of more than one hundred persons from across Canada, as well as Canadians and interested persons living in other parts of the world. The Society plans to sponsor conferences, to make future issues of Canadian Studies in Population available as a privilege of membership, and to begin issuing a newsletter in the near future. A membership campaign which is about to be launched is expected to increase the Society's numbers substantially, in view of the ease with which charter members were recruited.

In the same issue, Sylvia Wargon (1974:155), a historian of Canadian demography, reported that,

The Canadian Population Society held its first meeting in Toronto on August $22^{\text {nd }}, 1974$. A draft constitution was approved and a program of work for the 1974/75 year was adopted. The objectives of the society include improvement of the understanding of various aspects of population in Canada, and promotion of research and exchange of ideas among professionals working or interested in the field of population. ${ }^{7}$ 
Frank Trovato

The goals of the newly formed association were clearly spelled out, which were: (1) to affiliate with the French-speaking l'Association des Demographes du Quebec, (2) for the two associations to merge into a federation as to unite the two branches into a Canada-wide framework wherein joint conferences would be organized and publications sponsored in both languages, and "operations could be conducted at a truly national level"; (3) to create a forum for scholars of Canadian population where they could routinely present and discuss their research among an audience of like professionals; (4) to create an associations that would represent the interests of Canadian demographers in order to further develop the discipline of demography in Canada (Macleod, 1974: 147-48).

From these early announcements one gets a strong sense of excitement and optimism, that something of lasting value to the demographic community and to the larger Canadian society had been formed.

\section{The Sociohistorical Context}

Sociology teaches us that major developments in society occur in a social historical context. In my estimation, six key sociohistorical forces underlie the birth of the CPS:

(1) The development of a critical mass of academic demographers in the rapidly expanding Universities of the 1960s and early 1970s in Quebec and the rest of Canada.

(2) The growing body of professional demographers employed in government bureaus in Quebec and English Canada during the 1970s (e.g., Statistics Canada, Institut de la Statistique du Quebec).

(3) The important imprint on Canadian demography of influential scholars like Nathan Keyfitz, Norman Ryder, and Jacques Henripin. (Keyfitz and Ryder began their illustrious careers in Canada). Through their early and subsequent works these scholars (along with others in Canada) helped establish the relevance of demography in Canada and internationally.

(4) The growing recognition during the 1960s and early seventies among academic leaders across major Canadian universities that demography is an important field of study, in a context of rapid global population growth and widespread media attention to the so-called "population problem." 
The Canadian Population Society at Age Thirty: A Retrospective and Prospective

(5) The establishment of academic centers for demographic research and training in a number of prominent Canadian universities, namely the University of Montreal, The University of Western Ontario, University of Alberta, Carleton University, and University of Toronto.

(6) The increasing recognition among academics and policy officials that Canada's unique multicultural and multiethnic history dictates systematic scientific study by population experts to help formulate appropriate policies, such as those in connection with immigration.

These six conditions (and others) coincided in the late 1960s and early seventies to promote the idea that demography is of major academic and practical importance and that students, at all levels of study, would gain significantly by including demography as part of their course programs. Some universities in Canada acted on this recognition by hiring academic demographers from the United States and other parts of the world during the expansionary days of the 1960 s. Thus, by the early 1970s a critical mass of active professional demographers had been established in Canada. As explained by Sylvia Wargon (2002) in her Demography in Canada in the Twentieth Century, many of these professionals had assumed posts in the universities; others took positions in government bureaus, such as Statistics Canada, and the provincial and municipal departments of government. In the words of Parameswara Krishnan, during this time demographers in Canada began to question: "Why must we travel outside our country in order for us to meet professionally? Why can't we have our own demographic association?" According to Krishnan, the idea for the formation of a Canadian demographic association surfaced informally in New Orleans, in the context of the PAA's annual meetings in 1973. Krishnan explains:

At the PAA in New Orleans in 1973, myself, Eddie Ebanks, Ron D'Costa, and several other colleagues from Statistics Canada met informally in a restaurant after the daily sessions had closed. The idea came up that we should form our own Canadian demographic association. In those days, population/demography was usually included as part of the annual meetings of the Canadian Sociology and Anthropology Association. We felt that we had enough demographers in Canada to create a separate professional body of experts that could more effectively promote the interests of Canadian demography. ${ }^{8}$ 
Additional factors can be identified as contributing to the formation of the CPS. Sylvia Wargon (2002) indicates that by the mid to late 1960s, scholars at the University of Montreal (i.e., Jacques Legare, Jacques Henripin, Hubert Charbonneau, among others), had successfully created an independent program in demography (and the only one so identified), offering a wide variety of courses in the field; at the University of Western Ontario (i.e., John Kantner, T.R. Balakrishan, and others) a core of demography courses and a population studies center had been developed; and at the University of Alberta, (Warren Kalbach, with the assistance of Wayne McVey, and later Karol Krotki and P. Krishnan) the Population Research Laboratory had been launched and a variety of courses in population were being taught by an expanding core of demographers. Important demographic research was being conducted in these academic centers, ranging from genealogical studies of the French Canadian population, to surveys of fertility and family planning across selected Canadian metropolises.

Important as they were, these developments could not by themselves have made a major impact toward the establishment of Canadian demography, were it not for the energy and vision exercised by that generation of demographers in the late 1960 s and early 1970 s, and their ability to convince upper-level university administrators of the importance of supporting demography. This point is lucidly illustrated by the brief, yet expressive letter of Dr. E. Gunning, President of the University of Alberta in 1974, introducing the fledgling issue of Canadian Studies in Population:

"The importance of the study of human population need hardly be stressed under present-day world conditions. The recent World Population Conference at Bucharest and the Food Conference at Rome have brought to light the pressing problems of the underdeveloped visà-vis the developed nations. Canada has to and does play an important role in bridging the gap between the haves and the have-nots. This does not mean however that Canada can neglect her own population issues and concerns. The open-door immigration policy and the preservation of the historic heritage of the various streams of culture that flow into this country can all be self-defeating, if proper solutions are not determined. There are also issues such as metropolitanization, housing shortages, crime, which have to be given due consideration. The role of population scientists in this context becomes significant. Their research findings go to help the policy decision-makers come to grips with the problems. 
The Canadian Population Society at Age Thirty: A Retrospective and Prospective

In summary, this brief sketch of the sociohistorical context suggests that a series of favorable conditions in the 1960s coincided, which in their totality helped establish the groundwork for the founding of the Canadian Population Society (followed soon by the creation of the FCD to "join" it with the French-speaking demographic society, Association des Demographes du Quebec, ADQ).

\section{The Canadian Population Society at Age Thirty}

Since its birth in 1974, the CPS has successfully conducted itself as a vibrant and active association. The promises of the founding members have been met: annual conferences are held and are usually well attended by demographers from across Canada; new members have been added over the years, a notable number being graduate students; the CPS and the ADQ have merged under the umbrella of the FCD, as the national body representative of Canadian demographers. Since 1974, there have been a total of 15 Executive Councils, each contributing something of lasting value to the CPS, Canadian demography, and the social sciences in general. Some examples come to mind: We have been instrumental in advising Statistics Canada during their census preparations; we helped with the Demographic Review in the mid to late 1980s; recently, we offered expert advice to SSHRC with regard to their plans for restructuring; we also provided valuable input to the Tri-Council Ethics Panel concerning issues of ethics and confidentiality in social science research. There have been many other contributions.

The CPS has collaborated with a variety of other scholarly associations. In the context of the annual meetings, there is an established tradition of holding joint sessions with the Canadian Sociology and Anthropology Association; CPS has also joined forces with the Canadian Home Economics Association, the Canadian Historical Society, Canadian Political Science Association, Canadian Geographic Society, and the Canadian Economic Association, among others. Various governmental departments collaborate with the CPS to hold special sessions at the annual meetings (e.g., Statistics Canada, Department of Indian and Northern Affairs, Employment and Immigration, etc.) Of significance in this regard is the important link that has been established recently with the Canadian International Development Agency (CIDA), which has been sponsoring sessions on population and development.

During the past two years, CPS has introduced daylong workshops on new methods for longitudinal data analysis and on the variety of micro longitudinal data sets produced by Statistics Canada. A collaborative understanding has been reached with the Population Association of America (PAA) to hold joint 
Frank Trovato

sessions at the annual PAA meetings. As part of that collaboration, the two associations also exchange information of common interest in their respective websites and newsletters. Finally, I would be remiss if I did not mention the huge success of the CPS student paper competition; it has worked well in attracting excellent research contributions from our student members.

Taken together, these developments (and perhaps others not noted) paint a fairly optimistic picture of our association. Although relatively small in membership, the CPS remains a very active and vibrant collectivity. What then, are the challenges for the future?

\section{Looking Ahead: The Challenge of Renewal}

Concerning the future, two challenges are of prime importance. The first of these concerns our ability to attract new members to ensure a continued renewal of the membership base. The first generation of CPS members is steadily reaching retirement. In fact, in recent years a notable number of illustrious colleagues have retired. This trend is bound to intensify. Although many of these colleagues remain active in the CPS as Emeriti members, we can all agree that a steady flow of new members is needed in order to maintain some level of growth. The second challenge may be less obvious: it concerns the changing nature of sociology and the impact this is having on Canadian academic demography, and indirectly, on the future of the CPS.

Our current membership database (2003) discloses the following profile of the CPS: The total membership is 164 ( 2 are institutional members). We are predominantly male in composition (i.e., $62 \%$-- 100 males and 62 females). Most of us are from Ontario (55\%); the majority is affiliated with academic or government research departments $(81 \%)$; sociology is the major field of training of our members (65\%); 27 are student members (16\%), while 18 of our colleagues are Emeriti (11\%). As shown in Figure 1, the number of members in recent years has stagnated and is showing signs of decline. In 1974, we began with an initial figure of about 100 members; this rose steadily to just below 200 in the early 1990s, at which point the general trend, although somewhat irregular, has been downward, fluctuating somewhere between about 180 and 160. The most important component of the membership base is the "regular" category. Thus the overall numbers are greatly affected by a change in this class of membership. There has been a rise in the number of student members in recent years---and this trend must be encouraged at all costs! The "institutional" category is clearly on the decline, but could be turned around with some effort. There are many government departments that rely on demographic data and analysis; these can easily be identified and then invited to joint the CPS. ${ }^{10}$ 


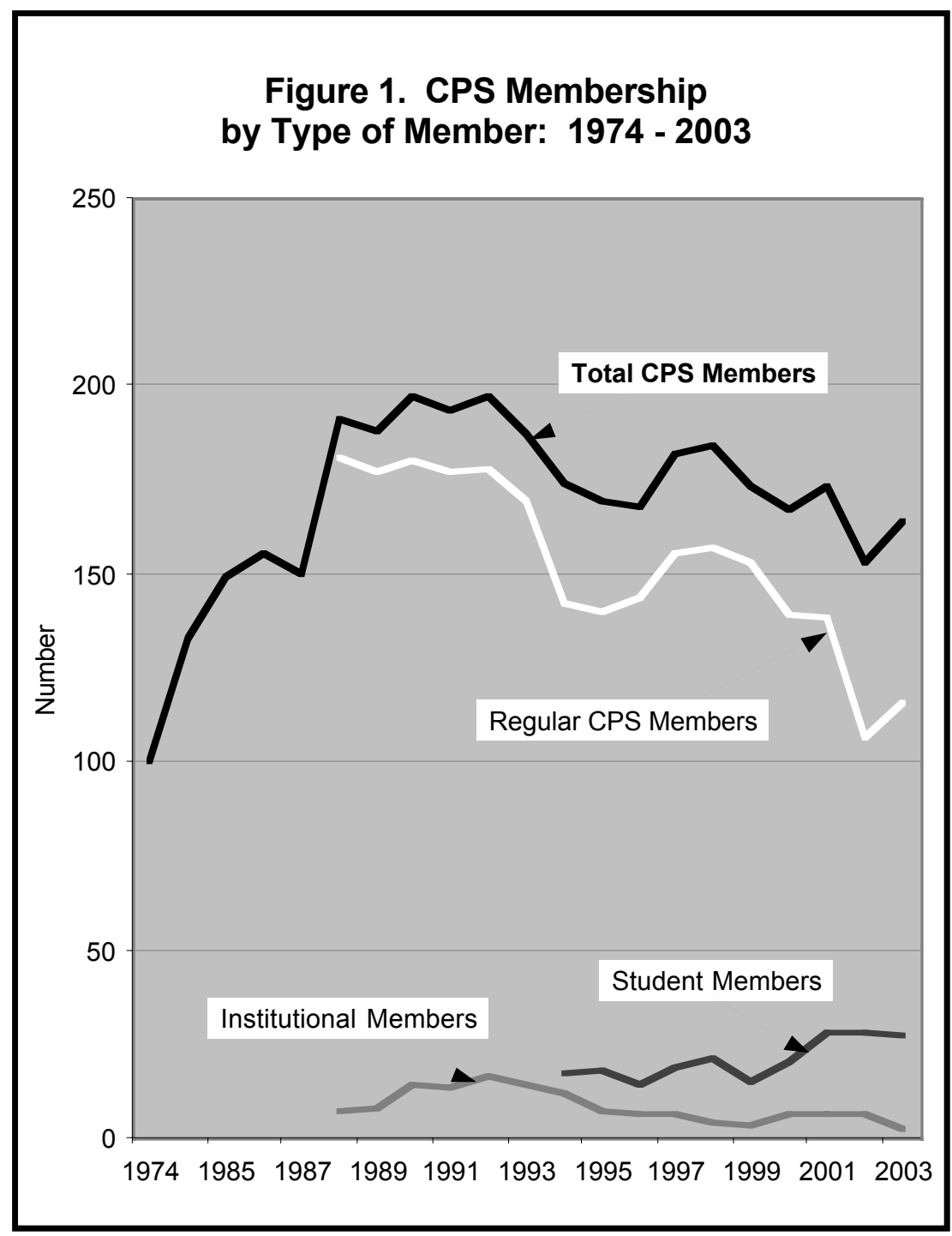

Note: Membership figure for 1974 is an estimate based on several accounts by various authors (i.e., MacLeod, 1974; Wargon, 2002). For the years 1984 to 1987, the only figures available are the over all totals. The category "student member" was introduced in 1994; and the "Emeriti" category was introduced in 2002. 
Frank Trovato

Demographers working in government departments at the municipal level remain an important and yet largely untapped source of new potential members. I suspect that many municipal departments would be highly interested in our association, and should be encouraged to join.

Critically important for the future of the CPS is the student membership class. I have not taken a detailed survey of the age breakdown of our membership contingent, but my sense is that many of us will be approaching retirement age over the next one or two decades. Many of the first generation members will join the ranks of the Emeriti. Therefore graduate students constitute the future of the CPS, and more broadly Canadian demography as an academic discipline. Therefore, we must attract student members. This however is largely contingent on our success in promoting the discipline of demography, especially in the university departments in which demography is traditionally taught in departments of sociology. Those of us in academia must continue, as professional demographers, to exert pressure on our respective departments to maintain demography as a central area of sociological study. And we must insist that retirements in this area be replaced with new faculty whose specialty is demography. ${ }^{11} \mathrm{~A}$ critical mass of demographers would ensure the viability of demography and also its ability to draw graduate students.

Serious consideration should be given to the possibility of the CPS expanding its recruitment efforts beyond the discipline of sociology. There are other university sectors from which potential members can be attracted---for example, Ecology, Actuarial Science, Public Health, Epidemiology, Geography, Economics, and Anthropology, among others. Promoting the interdisciplinary nature of our discipline can enhance the future of the CPS. Members of allied disciplines could be invited to join the CPS and to hold special interdisciplinary sessions at our annual meetings. This would help expand the CPS as a professional association that included not only sociologists and government scientists, but also researchers from the natural sciences and from a larger pool of social science disciplines. ${ }^{12}$

\section{Conclusion}

The CPS was founded 30 years ago in a favorable socio-historical context, at a time in which demography in Canada emerged as an important academic and policy oriented discipline. During its first three decades the CPS became a vibrant and vigorous association. Though small in numbers, it contributes significantly to the vitality of the social sciences in Canada. Notwithstanding these positive features, its membership base seems to have stagnated in recent years. Since the early 1990s the overall number of members has stabilized and is 
The Canadian Population Society at Age Thirty: A Retrospective and Prospective

showing signs of decline. In this brief overview I have identified some of the challenges that confront the discipline of Canadian demography and indirectly the CPS. Some possible avenues have also been identified to help meet the challenge of a declining membership base. The future of the CPS lies in its ability to continue to recruit new members, particularly graduate students. Currently, this important avenue for renewal is being hindered by the increasing marginalization of academic demography within the broader field of sociology across some universities more than others. Academic demographers must convince their departments to replace those who have retired with new faculty specifically in demography. Only in this way can more students be recruited to the discipline and hopefully also to the CPS. The CPS can also try to recruit new members from a variety of allied disciplines, and from government departments at the federal, provincial and municipal levels. Given the interdisciplinary nature of demography, the CPS should foster stronger links with these allied disciplines and government sectors.

\section{Acknowledgements:}

Many thanks to Sylvia Wargon who offered expert comments and valuable suggestions for revision on an earlier draft of this address. Thanks also to P. Krishnan and Catherine Krull for their comments. It goes without saying that responsibility for the contents of this address rests solely with the author.

\section{End Notes:}

1 According to the Museum of Fine Art in Boston, Gauguin sought to capture an inner world of fantasy and dream and considered this enormous canvas, created in Tahiti, his masterpiece. He indicated that the painting should be read from right to left, with the three major figure groups illustrating the questions posed in the title. The three women with a child represent the beginning of life; the central group symbolizes the daily existence of young adulthood; and in the final group, according to the artist, "an old woman approaching death appears reconciled and resigned to her thoughts"; at her feet "a strange white bird represents the futility of words." Yet, as so often in Gauguin's work, the whole remains mysterious: "Explanations and obvious symbols would give the canvas a sad reality," Gauguin wrote, "And the questions asked [by the title] would no longer be a poem." (From the Website of Museum of Fine Art in Boston: http://www.mfa.org/ accessed May 31, 2004). 
1 In Canada, the exception to this is the University of Montreal, where demography is an independent department, a situation that prevails in some parts of Europe (e.g., the University of Rome, "La Sapienza").

1 See Beaujot (2003: 119) for a similar observation.

1 For further analysis on this topic, see the recent issue of Genus on the teaching of demography in Europe and North America, edited by Caselli (2002).

1 If there is a foundational principle guiding postmodernism as a theoretical perspective, it is that knowledge is socially constructed and therefore all forms of knowledge and of ways of obtaining knowledge are equally valid (but see the devastating critique of postmodern theory by Alan Sokol and Jean Bricmont, 1999).

1 Although this is perhaps outside the boundaries of this address, I am of the opinion that sociology cannot move ahead as a scientific discipline unless quantitative methodologies, including formal demography, are brought back to center stage, along with sociological theory. This is by no means an original view (see for example the excellent collection of papers by Hedberg and Swedberg (1998) on this issue). This point is forcefully presented by Aage Soorensen (1998: 238), who writes: "I believe the integration of theory and evidence is important and that sociology will never move up from its humble position in the hierarchy of science unless we achieve a better integration between reliable knowledge and powerful theory. Further, since I am a quantitative sociologist, I believe that although qualitative approaches are important for the development of powerful theory, knowledge produced by qualitative research will never be sufficiently reliable and generalizable to satisfy the requirements for a complete scientific theory."

1 Wargon (1974: 155) noted that, "Preparations for the first meeting and a charter membership drive were conducted by a steering committee led by Ronald D'Costa and Betty Macleod. In a mailed ballot charter members elected the first slate of officers: Leroy O. Stone (President), Ronald D'Costa (Vice-President), Sylvia T. Wargon (Secretary-Treasurer), Marion Powell (Councillor), Alan B. Simmons (Councillor). Betty Macleod and P. Krishnan are steering committee members who will also serve on the first council."

$1 \quad$ P. Krishnan (personal communication). 
The Canadian Population Society at Age Thirty: A Retrospective and Prospective

1 E. Gunning (1974: iii), letter introducing the first issue of Canadian Studies in Population.

1 In this connection it would also be important to contact the centers of excellence on immigration (Toronto, Montreal, Edmonton, Vancouver) to invite them to become CPS institutional members. Other centers of excellence in a variety of research areas exist; these should also be contacted.

1 If demographers in such departments are not replaced with new demographers, those few that remain would find it increasingly difficult to sustain a program of demographic training. This can be a pernicious problem, as in the long-term it would lead to a deficit of graduate students, and academic demography would fall deeper into marginality.

1 This idea is not devoid of risk, however. The CPS is a small tightly-knight association, consisting mainly of sociologists from English-speaking Canada and from government departments. It is a congenial group that has developed a unique identity. The smallness of our association, as it were, is part of who we are. Reaching out to other disciplines may entail some erosion of "comfort." We may lose the identity that has been created over the years, as a small community of demographers mainly trained in sociology, especially in English-speaking Canada, but nevertheless, it should be tried, perhaps gradually.

\section{References:}

Beaujot, Roderic. 2003. Book Review of Demography in Canada in the Twentieth Century (Sylvia Wargon, author). Population Studies 57 (1): 118-119.

Caselli, Graziella. 2002. Teaching Demography in the Early $21^{\text {st }}$ Century. Special issue of Genus. Volume LVIII (3-4).

Hedstrom, Peter and Richard Swedberg (Editors). 1998. Social Mechanisms: An Analytical Approach to Social Theory. Cambridge: Cambridge University Press

Macleod, Betty. 1974. "History and Background on Population Activities in Canada." Canadian Studies in Population 1: 147-152. 
Frank Trovato

Sokal, Alan and Jean Bricmont. 1999. Fashionable Nonsense: Postmodern Intellectual's Abuse of Science. New York: Picador Press.

Soorensen, Aage B. 1998. "Theoretical Mechanisms and the Study of Social Processes," in Peter Hedstrom and Richard Swedberg (Editors), Social Mechanisms: An Analytical Approach to Social Theory. Cambridge: Cambridge University Press,. pp. 238-266

Veneziano, Gabriele. 2004. "The Myth of the Beginning of Time." Scientific American (May): 55-65.

Wargon, Sylvia. 2002. Demography in Canada in the Twentieth Century. Vancouver, BC: The University of British Columbia Press.

Wargon, Sylvia. 1974. "Canadian Population Society." Canadian Studies in Population 1: 147-152. 